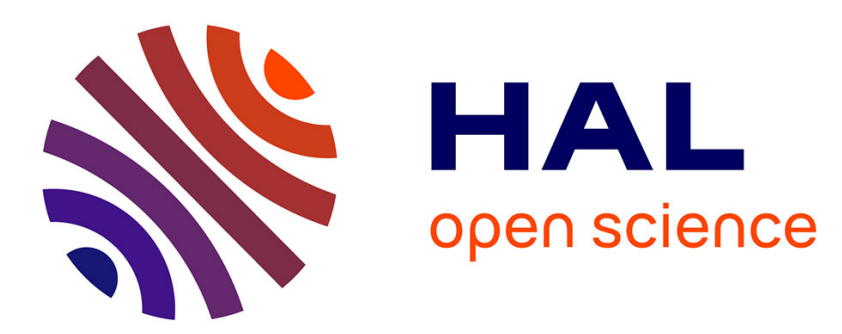

\title{
Experimental study of the instationary flow between two ducted Counter-rotating rotors
}

Hussain Nouri, Amélie Danlos, Florent Ravelet, Farid Bakir, Christophe Sarraf

\section{To cite this version:}

Hussain Nouri, Amélie Danlos, Florent Ravelet, Farid Bakir, Christophe Sarraf. Experimental study of the instationary flow between two ducted Counter-rotating rotors. Journal of Engineering for Gas Turbines and Power, 2013, 135 (2), pp.022601. 10.1115/1.4007756 . hal-00713761v3

\section{HAL Id: hal-00713761 \\ https://hal.science/hal-00713761v3}

Submitted on 20 Dec 2012

HAL is a multi-disciplinary open access archive for the deposit and dissemination of scientific research documents, whether they are published or not. The documents may come from teaching and research institutions in France or abroad, or from public or private research centers.
L'archive ouverte pluridisciplinaire HAL, est destinée au dépôt et à la diffusion de documents scientifiques de niveau recherche, publiés ou non, émanant des établissements d'enseignement et de recherche français ou étrangers, des laboratoires publics ou privés. 


\title{
Experimental study of the instationary flow between two ducted Counter-rotating rotors
}

\author{
H. Nouri, A. Danlos, F. Ravelet, F. Bakir, and C. Sarraf \\ Arts et Metiers ParisTech, DynFluid Lab., 151 boulevard de l'Hôpital, 75013 Paris, \\ France.
}

\begin{abstract}
An experimental study on counter-rotating axial-flow fans was carried out. The fans of diameter $D=375 \mathrm{~mm}$ were designed to match the specification point using an original method. The counter-rotating fans operate in a ducted-flow configuration and the overall performances are measured in a normalized test bench. The rotation rate of each fan is independently controlled and the axial spacing between rotors can be varied from $S=10$ to $S=180 \mathrm{~mm}$. Systematic measurements of the global performances and local measurements of the velocity field and of the wall pressure fluctuations are performed, in order to first validate the design method, and to explore the effects of the two specific free parameters of the system: the axial spacing and the ratio of rotation rates. The results show that the efficiency is strongly increased compared to a conventional rotor or to a rotor-stator stage. The developped design method slightly over-predicts the pressure rise and slightly under-predicts the best rotation ratio. The system is moreover highly efficient on a wide range of flow-rates and pressure rises: this system has thus a very flexible use, with a large patch of high efficient operating points in the parameter space.
\end{abstract}

\section{Atmospheric}

\section{INTRODUCTION}

Early studied in the 1930 's ${ }^{1,2}$, the counter-rotating machines arouse a greater interest in the turbomachinery field, particularly for their potential improvement of the efficiency with respect to conventional machines by recovering more kinetic energy from the front rotor exit-flow ${ }^{3-6}$. The first counter-rotating machines have appeared in aeronautic and marine applications, in open configuration. Nowadays, these machines with two coaxial axial-flow fans that rotate in opposite direction see a revival of interest in several distinct configurations - open and ducted flows, shrouded or not shrouded rotors - in various subsonic regime applications ${ }^{7-9}$.

The previous studies concluded that the presence of the rear rotor improves the global efficiency ${ }^{3,4}$ and also increases the operating flow-rate range. In the case of two counter-rotating rotors, there are at least two supplementary parameters that can influence the behaviour of the system: the axial spacing between the two rotors, and the possibility of adjusting the rotation rate ratio. The axial spacing may have a strong influence both on the global and local performances of the system ${ }^{3,4}$. An increase of this parameter leads to a decrease of the efficiency on the one hand, and to a decrease of the acoustic noise on the other hand. It is thus necessary to cope with this parameter in view of optimising a counter-rotating fans system. Besides, in the case of two independent rotation rates, the variation of the rotation rate ratio may be a very interesting mean to widden the operating range. In the industry, the use of frequency inverters and of industrial robots is moreover becoming widespread in order to save energy, which may favour the development of a lot of industrial applications of counter-rotating fans system in the near future.
The general aim of our study is to contribute to the development of a fast and reliable design method for such systems that take into account the effects of the various supplementary free parameters.

A system with two counter-rotating axial-flow fans in a ducted flow configuration has been designed according to an original method developped in the DynFluid Laboratory ${ }^{10}$. The two rotors can rotate independently and the distance between the rotors can be varied on a wide range. The first results show that the overall performances at the nominal design point are slightly lower than predicted, with a static pressure rise $10.2 \%$ lower. The static efficiency is however remarkably high $\left(\eta_{s} \simeq 65 \%\right)$ and corresponds to a 20 points gain in efficiency with respect to the front rotor maximal efficiency and to a 10 points gain with respect to the rear rotor. The overall measurements give first clues that allow to validate the design method. The first results on the effects of the rotation rate ratio and the axial spacing moreover confirm that the counter-rotating system has a very flexible use that allows to work at constant flow-rate on a wide range of static pressure rises or to work at constant pressure rise on a wide range of flow-rates, with static efficiency bigger than $60 \%{ }^{10}$.

This Article first presents an extension of the study of the global performances to a wider range of relative axial spacings $A$ and rotation rate ratios $\theta$. Emphasis is then placed on the interaction between the two rotors through local measurements of the velocity field with Laser Doppler Anemometry and local measurements of the wall pressure fluctuations on the casing. These local measurements give new light to the effects of the parameters $A$ and $\theta$ on the performances.

The method that was specifically developped is first briefly presented in $\S$ II. The experimental setup is then described in $\S$ III. The global performances of the system for the design parameters are given in $\S$ IV A. The effects of the axial spacing $S$ on the local features are explored 
TABLE I. Design point of the counter-rotating system for air at $\rho=1.21 \mathrm{~kg} \cdot \mathrm{m}^{-3}$

\begin{tabular}{llll}
\hline & CRS & Front Rotor & Rear Rotor \\
\hline \hline$D(\mathrm{~mm})$ & 380 & 380 & 380 \\
\hline$R_{t i p}(\mathrm{~mm})$ & 187.5 & 187.5 & 187.5 \\
\hline$R_{h u b}(\mathrm{~mm})$ & 55 & 55 & 55 \\
\hline$Z$ & - & 11 & 7 \\
\hline$\Delta p_{t}(\mathrm{~Pa})$ & 420 & 260 & 160 \\
\hline$N(\mathrm{RPM})$ & 1900 & 2000 & 1800 \\
\hline$Q\left(\mathrm{~m}^{3} \cdot \mathrm{s}^{-1}\right)$ & 1 & 1 & - \\
\hline$\Omega=\frac{\omega \sqrt{Q}}{\left(\Delta p_{t} / \rho\right)^{3 / 4}}$ & 2.46 & 3.71 & - \\
\hline Other constraints Axial exit-flow Constant vortex & $\begin{array}{c}\alpha_{1 R R}(r)=\alpha_{2 F R}(r) \\
C_{a 1 R R}(r)= \\
C_{a 2 F R}(r)\end{array}$ \\
\hline
\end{tabular}

in $\S$ IV B. The potential of improving the performances with adjusting the rotation rate ratio $\theta$ is then discussed in $\S$ IV C. Finally, conclusive remarks are given in $\S \mathrm{V}$.

\section{DESIGN OF THE ROTORS}

The design of the rotors is based on the use of the software MFT (Mixed Flow Turbomachinery) developed by the DynFluid Laboratory ${ }^{11}$ to which an original method has been added specifically for the design of the rear rotor of the counter-rotating system ${ }^{10}$.

The design point of the Counter-Rotating System (CRS) is given in Tab. I. The system is designed to achieve a total-pressure rise $\Delta p_{t}=420 \mathrm{~Pa}$ at flow-rate $Q=1 \mathrm{~m}^{3} \cdot \mathrm{s}^{-1}$ for a mean rotation rate $N=1900 \mathrm{rpm}$. The CRS is moreover constrained to have a solely axial discharge flow at the nominal flow-rate.

The two rotors, i.e. the front rotor $(\mathrm{FR})$ and the rear rotor $(\mathrm{RR})$, are then designed following an iterative procedure:

- The pressure rise of the front rotor is initially chosen and FR is designed with the MFT software, that is based on the inverse method with simplified radial equilibrium ${ }^{11}$.

- The behaviour of the designed FR is then analysed with MFT, using a direct method. The effects of the real fluid are partially taken into account with the introduction of an axial-velocity distribution which considers the boundary layers at the hub and casing. If the design point is not met, the blade cascade can be slightly modified by hand, for instance by changing the value of the hub and tip Lieblein's diffusion factors or the number of blades.

- The total pressure rise of FR $\Delta p_{t F R}$ is computed. The axial and tangential velocities $\left(C_{a 2 F R}=\right.$ $C_{a 1 R R}$ and $C_{u 2 F R}=C_{u 1 R R}$ respectively) and the flow angle $\alpha_{2 F R}$ at the trailing edge of the FR blades are also computed (see Fig. 1). The RR is drawn in such a way that the exit flow is purely axial, that is $\alpha_{2 R R}=0^{\circ}$, using a Matlab script, assuming that the axial velocity profile is kept constant across RR, i.e. $C_{a 2 R R}(r)=C_{a 1 R R}(r)$. Under these assumptions, the total pressure rise of RR should be $\Delta p_{t R R}=\eta_{\text {est }} \rho U_{m R R} C_{u 2 F R}$, with $\eta_{\text {est }}=60 \%$ an estimate of the rotor efficiency.

- The total pressure rise of the CRS is computed as $\Delta p_{t C R S}=\Delta p_{t F R}+\Delta p_{t R R}$. If the design point is not met, the design pressure rise of $F R$ is varied and the calculus are made again.

The drawback of this method is that the losses and interactions in-between the two rotors are not taken into account. The effects of the axial spacing $S$ in particular are not taken into account. In the present case, this direct analysis of $\mathrm{FR}$ predicts a mean absolute tangential velocity downstream of the front rotor $C_{u 2 F R} \simeq 9.6 \mathrm{~m} . \mathrm{s}^{-1}$ with a radial distribution uniform within $\pm 5 \%$ (constant vortex design) at the design flow-rate. The Reynolds number based on the inlet relative velocity and on the chord length varies from $0.6 \times 10^{5}$ at the hub to $3 \times 10^{5}$ at mid-span and $7 \times 10^{5}$ at the tip. The geometrical characteristics of the rotor blades obtained with this method are summarized in Tab. II, and pictures of the front and rear rotors are given in Fig. 2. The profiles of $C_{a 2 F R}(r)$ and $C_{u 2 F R}(r)$ computed with MFT, on which the design of $\mathrm{RR}$ is based, are plotted in Fig. 5 .

The behaviour of the designed machine resulting from the above method can then be measured in order to answer the following questions:

- Is the design-point achieved?

- What are the characteristics of the machine at the neighbourhood of the design point? 

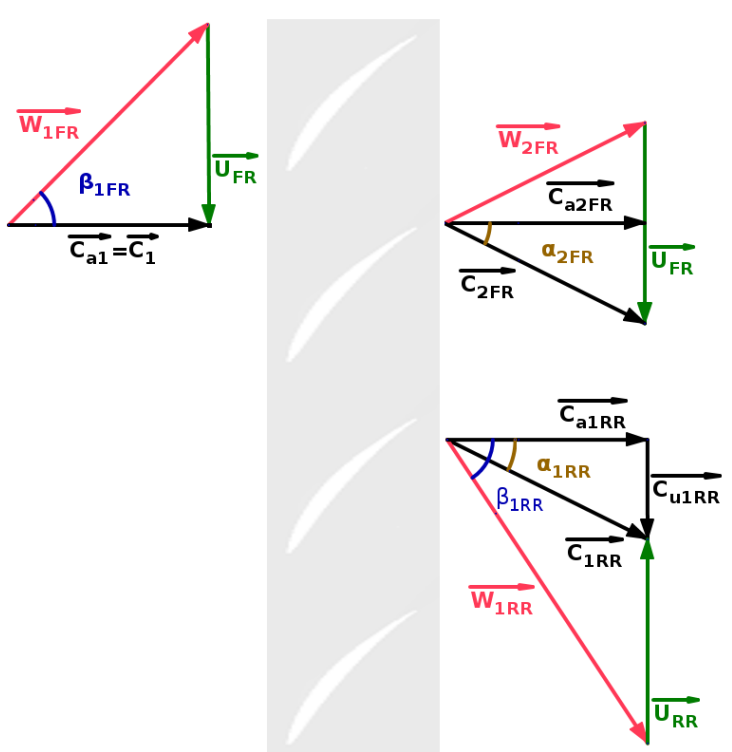

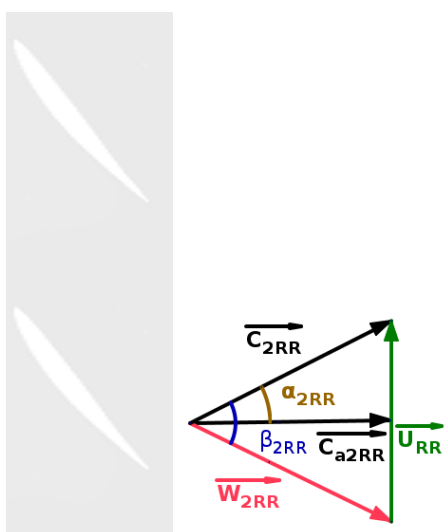

FIG. 1. Velocity Triangles for the CRS. The fluid is flowing from left to right. Please see the Nomenclature for the meaning of the capital letters and subscripts. Please also note that this is a general case where the exit-flow is not constrained to be solely axial

TABLE II. Blade cascade parameters for the two rotors. Radius $R(\mathrm{~mm})$. Chord length $c(\mathrm{~mm})$. Cascade solidity $\sigma$. Stagger angle $\gamma\left({ }^{o}\right)$. Profile designation according to the nomenclature given in Ref. ${ }^{11}$ : NACA65(xx)yy with (xx) representing the relative camber and yy standing for the relative thickness. Lieblein's diffusion factor $\mathcal{D}$

\begin{tabular}{|c|c|c|c|c|c|c|}
\hline Radial position & $R$ & $c$ & $\sigma$ & $\gamma$ & profile & $\mathcal{D}$ \\
\hline \multicolumn{7}{|c|}{ Front Rotor (blade thickness $4.5 \mathrm{~mm}$ ) } \\
\hline Hub & 55 & 40.3 & 1.28 & 23 & NACA $65(26) 11$ & 0.62 \\
\hline Mid-span & 121.25 & 58.0 & 0.84 & 57 & NACA $65(12) 07$ & \\
\hline Tip & 187.5 & 75.7 & 0.71 & 69 & NACA $65(07) 06$ & 0.44 \\
\hline \multicolumn{7}{|c|}{ Rear Rotor (blade thickness $6 \mathrm{~mm}$ ) } \\
\hline $\mathrm{Hub}$ & 55 & 58.8 & 1.18 & 73 & NACA $65(03) 10$ & 0.61 \\
\hline Mid-span & 121.25 & 72.9 & 0.66 & 65 & NACA $65(05) 08$ & \\
\hline Tip & 187.5 & 87.1 & 0.51 & & NACA $65(04) 07$ & 0.46 \\
\hline
\end{tabular}

\section{EXPERIMENTAL SET-UP}

\section{A. Test bench}

The counter-rotating system is studied in a ducted-flow test rig - $\mathrm{AERO}^{2} \mathrm{FANS}$ - that has been built according to the ISO-5801 standards (installation of category B) ${ }^{12,13}$. The Figure 2 shows this test rig. It consists of a cylindrical pipe of inner diameter $D=380 \mathrm{~mm}$. A bell mouth is flush-mounted at the inlet of the duct to reduce the energy loss due to fluid friction and flow separation of the inlet flow. The upstream face of FR is at a distance $5 D$ from the pipe inlet. A honeycomb is placed upstream of FR to homogenize the incoming flow. Two brushless PANASONIC A4 motors drive each rotor separately and are hidden in a casing of diameter $0.33 \mathrm{D}$ and of length $0.45 D$, with a warhead-shape end. The front and the rear motors are bound to the tube by two rod rows ( 3 and 5 rods, the first row being at $0.1 D$ from the rear rotor). For the front motor the honeycomb is placed between the two rows to reduce the rods effect on the incoming flow at the inlet of the FR. An antigyration device made of eight metal sheets of thickness $1.5 \mathrm{~mm}$ and length $2 D$ is placed $2 D$ downstream of the CRS. It prevents the outgoing flow from having any ro- 

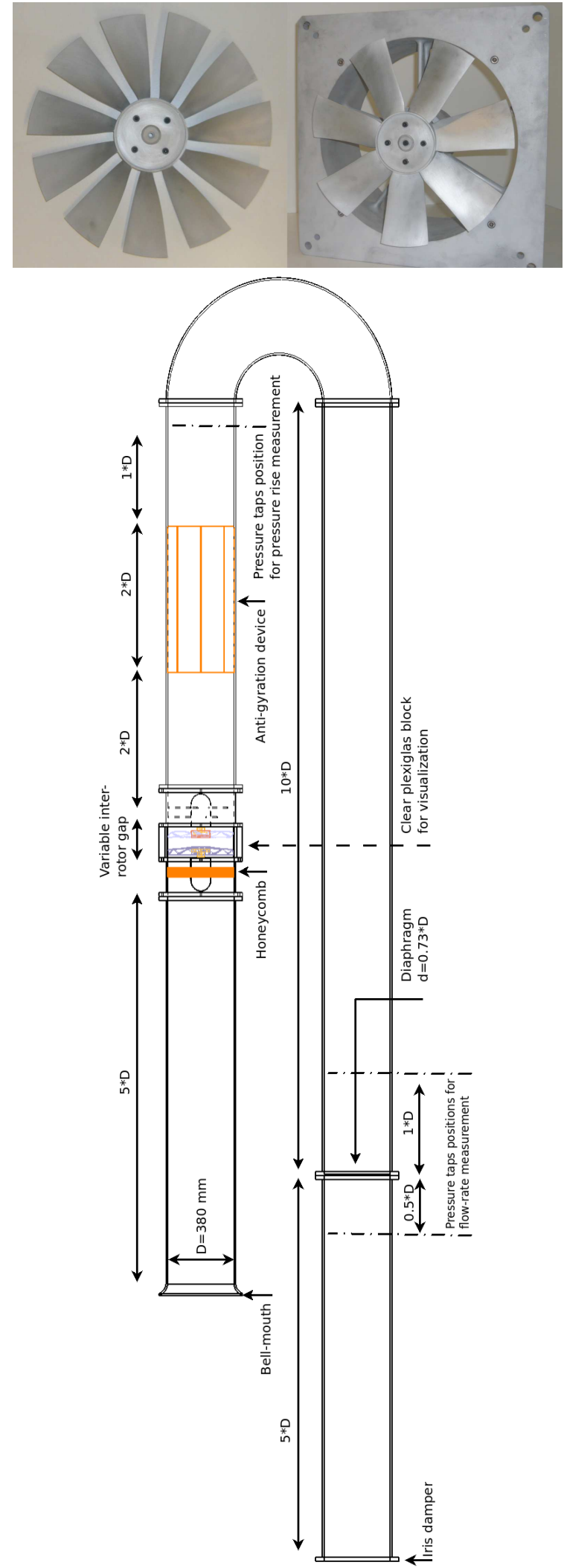

FIG. 2. Experimental facility for CRS, $A E R O^{2} F A N S$ tating component by converting the dynamic pressure of the rotational component to thermal energy. Therefore, as the outgoing flow is supposed to contain only axial component, perpendicular to the pressure taps with no radial dependance, the static pressure that is measured $1 D$ downstream of the anti-gyration device, with an average over four flush-mounted pressure taps, is equal to the average pressure in the section. To make the installation more compact, a tube bend of $180^{\circ}$ is placed $1 D$ downstream of the pressure taps. The flow rate is measured with a normalized diaphragm, located $10 D$ downstream of the tube bend and $5 D$ upstream of the pipe outlet. The diaphragm has a diameter of $0.73 D$. An iris damper originally used for air flow regulation in ducts - is placed at the exit of the pipe to vary the test-bench hydraulic impedance and thereby to vary the operating point of the studied axial-flow fan. Finally, an axial blower can also be used at the exit of the pipe to widen the explored flow-rate range.

\section{B. Measurements methodology and accuracy}

a. Control parameters: The study focuses on the influence of the gap between the rotors (axial spacing $S$ ) as well as on the influence of the ratio of rotation rates $\theta=\frac{N_{R R}}{N_{F R}}$. Six axial spacings, from $S=$ $10 \mathrm{~mm}$ to $S=180 \mathrm{~mm}$ were investigated. They correspond to relative axial spacings with respect to the chord of FR at mid-span $\left(c_{F R}=58 \mathrm{~mm}\right) A=$ $\frac{S}{c} \in[0.17,0.34,0.69,0.86,2.58,3.10]$. Blocks of different thickness are used to change the axial spacing. Unless specified the default axial spacing is $S=10 \mathrm{~mm}$ $(A=0.17)$.

Regarding the ratio $\theta$, each rotor is driven separately so all combinations are possible. The default configuration is $\theta=0.9$ (see Tab. I). The motors are driven with two servo-controllers with a close loop regulation that is excellent: their rotation rate is constant within $\pm 2 \mathrm{rpm}$.

b. Static pressure rise: According to the ISO-5801 standard $^{12}$, the static pressure rise is defined as the difference between the static pressure downstream of the fan and the total pressure at the duct inlet:

$$
\Delta p_{s}=p_{s R R 2}-p_{a t m}
$$

It is of practical interest for applications where a fan sucks air from the atmosphere and blows it into a circuit with an exit to the atmosphere (open circuit). In the present article, only the static pressure rise is considered and all figures relative to the CRS performances are performed with the above definition. The measurements are corrected with the static pressure drop due to the entrance loss, the honeycomb, the rotor casings and the anti-gyration device that has been measured separately - the rotors have been removed and the blower has been used to create a flow.

In the design of the CRS, it has been imposed a pure axial-flow at the exit of RR. In that specific case 
the static pressure rise of the CRS should be $\Delta p_{s}=$ $\Delta p_{t}-1 / 2 \rho\left(Q /\left(\pi D^{2} / 4\right)\right)^{2} \simeq 373 \mathrm{~Pa}$. The only way to measure the total pressure rise of the system in a general case that includes radial dependance of the discharge flow with axial, radial and tangential components is to measure the whole velocity and pressure fields on a section downstream of RR.

The atmospheric pressure, the dry temperature and the wet temperature have been measured. The density of the air is then computed for each measurement. It has been found that the maximum variation in density, relatively to the design density, $\rho_{\text {air }}=1.21 \mathrm{~kg} \mathrm{~m}^{-3}$ is $\pm 2.2 \%$. Therefore, in order to present homogeneous results, the pressure rise that is discussed in the following has been multiplied by the ratio of the design density $\rho_{\text {air }}$ over the experimentally measured density, $\rho_{\text {exp }}$, i.e. $\frac{\rho_{a i r}}{\rho_{\text {exp }}}$.

The static pressure rise is measured with an absolute precision of $\pm 1 \mathrm{~Pa}$. The correction for the losses also introduces an error of $\pm 3 \mathrm{~Pa}$. Finally, the relative uncertainty of the measurement of $\rho$ is $\pm 1 \%$. Therefore, the errorbars that are displayed in the following figures for the static pressure rise stand for the uncertainty of the normalised pressure rise, computed using standard uncertainty evaluations methods.

c. Volumetric flow-rate measurement: The measurement of the volumetric flow-rate is done by measuring a singular pressure drop $\Delta p_{\text {diaph }}$ on a diaphragm: $Q \propto \sqrt{\Delta p_{\text {diaph }} / \rho}$. The relative uncertainty of the measured flow-rate is of the order of $\pm 0.5 \%$ at the nominal flow-rate.

d. Static efficiency: The static efficiency is defined by equation 1, with $Q$ the volumetric flow-rate, $\Delta P_{s}$ the measured static pressure rise, $T$ the torque and $\omega$ the angular velocity:

$$
\eta_{s}=\frac{\Delta P_{s} Q}{\left(T_{F R} \omega_{F R}\right)+\left(T_{R R} \omega_{R R}\right)}
$$

The torque $T$ was measured using the drivers provided with the motors. A calibration measurement has been performed with a conventional torque-meter. This calibration step shows that the measure of the torque supplied by the driver is very precise, the difference between the two measurements being below $\pm 0.5 \%$. The relative uncertainty of the static efficiency is of the order of $\pm 1 \%$.

e. Velocity measurements and flow visualization: Laser Doppler Anemometry (LDA) measurements have been performed locally in-between the rotors in order to study the influence of the axial spacing on the flow in this mixing region. The axial and tangential components of the velocity along the radial direction were measured using a one-component LDA system through a thin $(e=2.5 \mathrm{~mm})$ and flat window, integrated to the duct. Beside these local and instationary measurements, original measurement of the absolute flow angle were performed with a high speed camera and a thin wind vane. This method is inspired from the wool tufts visualization technique but instead of wool tufts, a small and light plate is used in order to determine the flow angle downstream of the rear rotor. The images are analysed with Matlab, using the pattern recognition algorithms described in Ref. ${ }^{14}$ in order to compute the average value of the absolute flow angle and its fluctuations.

$f$. Wall pressure fluctuations: Wall pressure fluctuations are measured simultaneously by four microphones that are evenly distributed on the circumference of the duct. They are mounted downstream of the front rotor, at various axial distances. The microphones are G.R.A.S 40BP 1/4" polarized pressure microphones of sensitivity 1.65 mv.Pa ${ }^{-1}$, with G.R.A.S $26 \mathrm{AC}$ preamplifiers and a G.R.A.S $12 \mathrm{AG}$ power supply module. The signals are amplified with a gain of $+30 \mathrm{~dB}$ and high-pass filtered with a three-pole Butterworth filter with cut-off frequency of $20 \mathrm{~Hz}$. The signals are then digitalized using a NI Data Acquisition Card (PCI 6123 S, with simultaneously sampled channels, 16 bits) at a sample rate of $6 \mathrm{kHz}$.

\section{RESULTS AND DISCUSSION}

\section{A. Overall performances of the reference system $(\{\theta=0.9 ; S=10 \mathbf{m m}\})$}
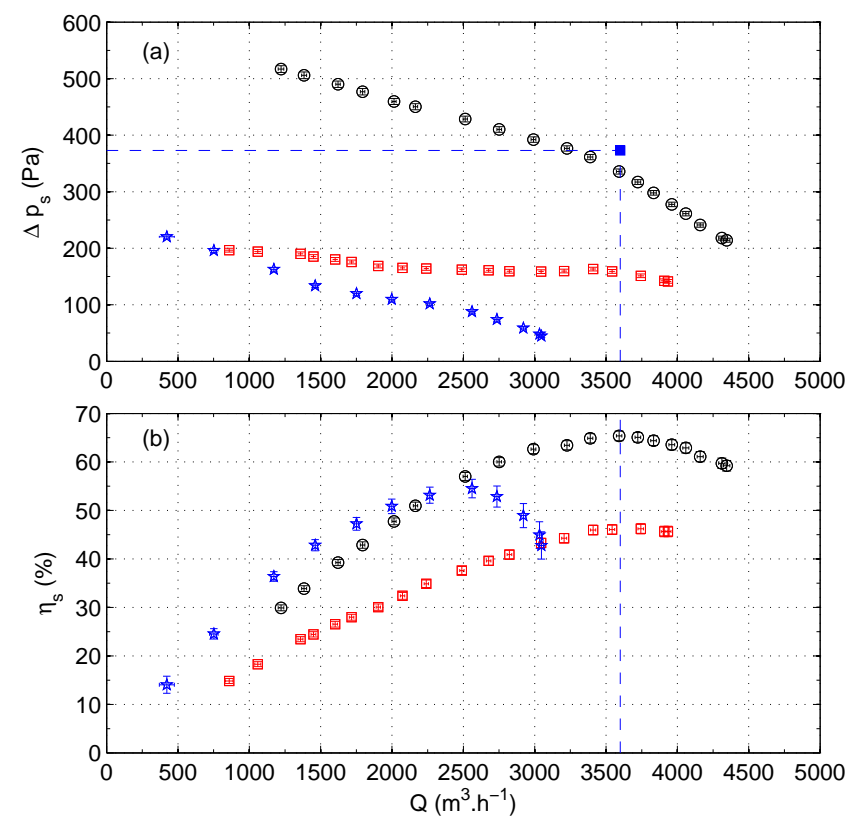

FIG. 3. Fans characteristics: (a) static pressure rise $\Delta p_{s}$ $v s$ flow rate $Q$; (b) static efficiency $\eta_{s}$ vs flow rate $Q$. The axial spacing is $S=10 \mathrm{~mm}$. Red $\square$ : FR rotating alone at $N_{F R}=2000 \mathrm{rpm}$ (RR has been removed), blue $\star$ : $\mathrm{RR}$ rotating alone at $N_{R R}=1800 \mathrm{rpm}$ (FR has been removed) and black o: CRS at $N_{F R}=2000 \mathrm{rpm}$ and $\theta=0.9$. The blue and the dashed lines stand for the design point of the CRS. The errorbars stand for the measurement uncertainty 
TABLE III. Nominal points of FR rotating alone at $N_{F R}=2000 \mathrm{rpm}, \mathrm{RR}$ rotating alone at $N_{R R}=1800 \mathrm{rpm}$ and CRS at $N_{F R}=2000 \mathrm{rpm}$ and $\theta=0.9$ (see also Fig. 3)

\begin{tabular}{clll}
\hline & \multicolumn{3}{c}{ Front Rotor } \\
\hline \hline Maximum efficiency $(\%)$ & $46.2 \pm 1$ & $54.4 \pm 1$ & $65.4 \pm 1$ \\
\hline nominal $Q\left(\mathrm{~m}^{3} \cdot \mathrm{s}^{-1}\right)$ & $1.01 \pm 0.01$ & $0.70 \pm 0.01$ & $1.00 \pm 0.01$ \\
\hline$\Delta p_{s}(\mathrm{~Pa})$ & $157 \pm 3$ & $88 \pm 3$ & $335 \pm 5$ \\
\hline
\end{tabular}

The characteristics of the $\mathrm{FR}$ rotating alone ( $\mathrm{RR}$ has been removed from its shaft in that case), of the RR rotating alone (FR has been removed) and of the counterrotating system are shown in Fig. 3. The operating rotation rates are the design rotation rates, i.e. $2000 \mathrm{rpm}$ for the front rotor and $1800 \mathrm{rpm}$ for the rear rotor. The nominal flow-rates of the three systems, i.e. the flowrates at maximum efficiency, are reported in Tab. III together with the corresponding static pressure rises and efficiencies.

The front rotor rotating alone has a very flat curve (red $\square$ in Fig. 3). The characteristic curve could not be explored for flow-rates higher than $3800 \mathrm{~m}^{3} \cdot \mathrm{h}^{-1}$, i.e. $1.06 \mathrm{~m}^{3} . \mathrm{s}^{-1}$, even with the help of the blower. The measured static pressure rise at the design point is $157 \mathrm{~Pa}$, with a relatively low static efficiency of $46 \%$. Numerical analysis performed with $\mathrm{MFT}^{11}$ and with Fluent 6.3 give very similar results for the static pressure rise $(142 \leq$ $\left.\Delta p_{s} \leq 153 \mathrm{~Pa}\right)$. The total pressure rise predicted by these two different numerical methods - a model using semi-empirical correlations vs Computational Fluid Dynamics - is roughly $260 \mathrm{~Pa}$. The predicted global performances of FR can thus be considered as validated. The remaining question is about the prediction of the exit-flow velocity components, i.e. of the exit-flow angles. The comparison of the predicted and measured velocity profiles is presented in $\S$ IV B.

The rear rotor rotating alone has a steeper curve (blue $\star$ in Fig. 3) and its nominal flow-rate $Q \simeq$ $2550 \mathrm{~m}^{3} \cdot \mathrm{h}^{-1}$ is lower than the design flow-rate of $\mathrm{FR}$ and CRS. First, this is consistent with the bigger stagger angle of the blades (see Tab. II). This rotor is not conventional. Let us remind that it has been designed to be adapted to a flow-rate $Q=1 \mathrm{~m}^{3} \cdot \mathrm{s}^{-1}$ with prerotation.

Let us examine the velocity triangles in Fig. 1 and consider the case with the front coupled to the rear rotor: the incoming velocity $\mathrm{C}_{1 R R}=\mathrm{C}_{2 F R}$ has an axial component as well as a tangential component. Hence, the flow angle in the relative reference frame reads:

$$
\tan \left(\beta_{1 R R}\right)=\frac{U_{R R}+C_{u 1 R R}}{C_{a 1 R R}}
$$

Let us consider now the case without the front rotor and assume that the flow through the honeycomb is axial. Since the tangential component does not exist any more and the incoming velocity has only the axial component, equation 2 becomes:

$$
\tan \left(\beta_{1 R R}\right)=\frac{U_{R R}}{C_{a 1 R R}}
$$

Let us now compute the result of equation 2 for the mean radius and at the nominal flow-rate of the CRS, assuming that the tangential velocity is well predicted by MFT, that is $\left\langle U_{R R}\right\rangle \simeq 22.9 \mathrm{~m} . \mathrm{s}^{-1},\left\langle C_{a 1 R R}\right\rangle \simeq 8.8 \mathrm{m.s}{ }^{-1}$ and $\left\langle C_{u 1 R R}\right\rangle=\left\langle C_{u 2 F R\rangle} \simeq 9.6 \mathrm{~m} . \mathrm{s}^{-1}\right.$. This leads to $\left\langle\tan \left(\beta_{1 R R}\right)\right\rangle \simeq 3.69$. If we now suppose that $\mathrm{RR}$ rotating alone has its maximum efficiency when the tangent of the inlet flow-angle is equal to this value, equation 3 implies that this is for a flow-rate such that $\left\langle C_{a 1 R R}\right\rangle=$ $\frac{\left\langle U_{R R}\right\rangle}{\tan \left(\left\langle\beta_{1 R R}\right\rangle\right)} \simeq 6.2 \mathrm{~m} . \mathrm{s}^{-1}$, i.e. $\quad Q \simeq 0.705 \mathrm{~m}^{3} \cdot \mathrm{s}^{-1}$ or $2540 \mathrm{~m}^{3} \cdot \mathrm{h}^{-1}$. This is exactly the nominal flow-rate of RR rotating alone (see Fig. 3 and Tab. III).

The characteristic curve of the CRS (black o in Fig. 3) is steeper than the characteristic curve of FR. It is roughly parallel to the RR curve. The nominal flowrate of the CRS matches well with the design flow-rate, i.e. $1 \mathrm{~m}^{3} \cdot \mathrm{s}^{-1}$. The static pressure rise at the nominal discharge $\left(\Delta p_{s C R S}=335 \mathrm{~Pa}\right)$ is $10.2 \%$ lower than the design point $(373 \mathrm{~Pa})$, which is not so bad in view of the rough approximations used to design the system.

The CRS has a high static efficiency $\left(\eta_{s C R S}=65 \%\right)$ compared to a conventional axial-flow fan or to a rotorstator stage with similar dimensions, working at such Reynolds numbers ${ }^{15,16}$. The gain in efficiency with respect to the front rotor is 20 points, whilst an order of magnitude of the maximum gain using a stator is typically 10 points $^{15,16}$. The efficiency curve is moreover very flat: the flow-rate range for which the static efficiency lays in the range $60 \% \leq \eta_{s} \leq 65 \%$ is: $2750 \lesssim Q \lesssim$ $4150 \mathrm{~m}^{3} \cdot \mathrm{h}^{-1}$, that is from $76 \%$ of the nominal flow-rate up to $115 \%$ of the nominal flow-rate. One open question is to what extent the global performances of the CRS are affected by the axial spacing and the ratio of rotation rates, and whether the efficient range could be extended by varying this ratio.

\section{B. Influence of the axial spacing $S$}

g. Global performances Figure 4 shows the characteristics curves at the design rotation rates, i.e., $N_{F R}=$ 

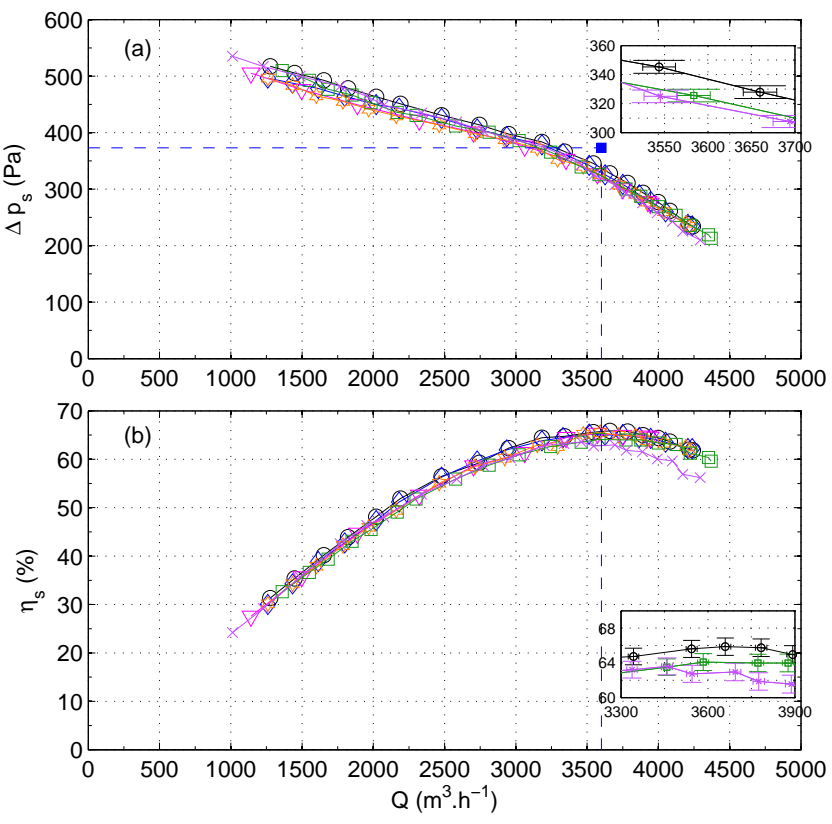

FIG. 4. CRS characteristics at various axial spacing: (a) static pressure rise $\Delta p_{s}$ vs flow rate $Q$; (b) static efficiency $\eta_{s}$ $v s$ flow rate $Q$. The rotation ratio of $\mathrm{FR}$ is $N_{F R}=2000 \mathrm{rpm}$ and $\theta=0.9$. Black $\circ: S=10 \mathrm{~mm}$, blue $\diamond: S=20 \mathrm{~mm}$, magenta $\nabla: S=40 \mathrm{~mm}$, orange $\star S=50 \mathrm{~mm}$, dark green $\square$ : $S=150 \mathrm{~mm}$, purple $\times: S=180 \mathrm{~mm}$. The blue $\mathbf{\square}$ and the dashed lines stand for the design point of the CRS

$2000 \mathrm{rpm}$ and $\theta=0.9$. For all axial spacings, the overall performances hardly change near the nominal flow-rate. They tend however to decrease by less than $5 \%$ when increasing $S$. The efficiency decreases by only 2 points and the nominal flow-rate (defined by the highest efficiency) does not change for the different cases. The axial spacing parameter $S$, does not seem to affect global performances. This would be the case if the axial and tangential components of the velocity fields do not vary significantly with $S$. This point is addressed in the following paragraph, where, unless specified, more local studies are performed at the design point of the system $\left(N_{F R}=2000 \mathrm{rpm}, \theta=0.9\right.$ and $\left.Q=1 \mathrm{~m}^{3} \cdot \mathrm{s}^{-1}\right)$.

$h$. Mean velocity field in between the two rotors Local LDA measurements of the axial and tangential components were performed along the span-wise direction for three axial spacings: $S=\{10 ; 50 ; 180\}$. The radial profiles at a distance $d=5 \mathrm{~mm}$ downstream of $\mathrm{FR}$ of the time-average of both components are plotted in Fig. 5 and compared to the values predicted by MFT ( $\square)$. First, the flow-rate that is computed with an integration of the axial velocity is $Q=1.00 \pm 0.02$ for all the presented cases, in excellent agreement with the flow-rate measured with the in-duct diaphragm. The measured axial profiles (Fig. 5(a)) are not homogeneous: the flow-rate is discharged mainly through the upper part of the blade. This tendency is slightly under-predicted by MFT. In
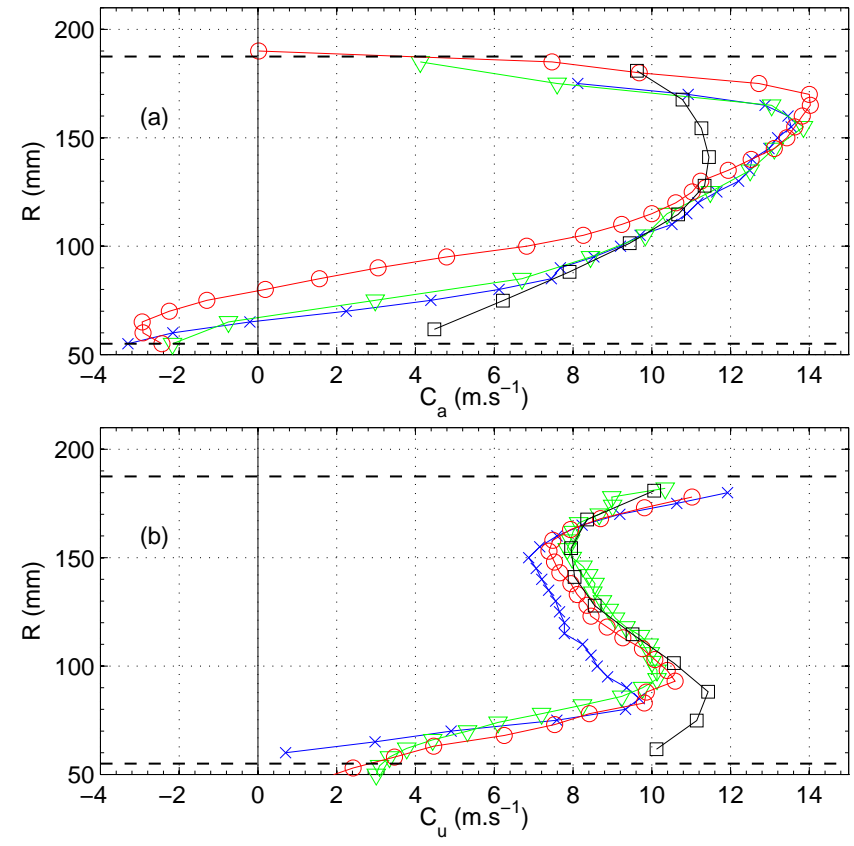

FIG. 5. Comparison of the radial profiles at a distance of $5 \mathrm{~mm}$ downstream of FR of the axial and tangential components, $C_{a}$ (a) and $C_{u}$ (b) respectively for $S=10 \mathrm{~mm}$ (blue $\times), S=50 \mathrm{~mm}($ green $\nabla)$ and $S=180 \mathrm{~mm}$ (red $\circ)$. The black $\square$ stand for the values predicted by MFT. The dashed lines represent the hub and the blade tip. $N_{F R}=2000 \mathrm{rpm}$ and $\theta=0.9$

the lower part of the blade, negative values of the axial velocity in the experimental profiles indicate a recirculating flow and thus the presence of a radial component at least in this region of the blade. This behaviour is not predicted with MFT, because of the simplified radial equilibrium hypothesis that forces the radial component to be equal to zero. The deficit in term of flow-rate shown by the measured profile in the lower region is counterbalanced by higher velocities in the upper region in comparison with the predicted values.

For $S=10 \mathrm{~mm}$ (blue $\times$ in Fig. 5) and $S=50 \mathrm{~mm}$ (green $\nabla$ ), the profiles are very similar whereas for $S=$ $180 \mathrm{~mm}$ (red o), the bigger spacing between the rotors seems to lead to a greater recirculation and the whole profile is slightly shifted to the upper part of the pipe.

Regarding the tangential component (Fig. 5(b)), the measured profiles are in good consistence with the predicted value from MFT particularly for $S=50 \mathrm{~mm}$ and $S=180 \mathrm{~mm}$. For the same reasons as for the axial component, in the lower region MFT is unable to detect the velocity deficit. For $S=10 \mathrm{~mm}$, the tangential velocity is lower than in the other two cases. This might be due to the proximity of the rear rotor: at each blade passage, the velocity is slowed down by the blade which results in an averagely lower value.

These profiles, measured $5 \mathrm{~mm}$ downstream of the FR, point out a local effect that may be due to the rear ro- 

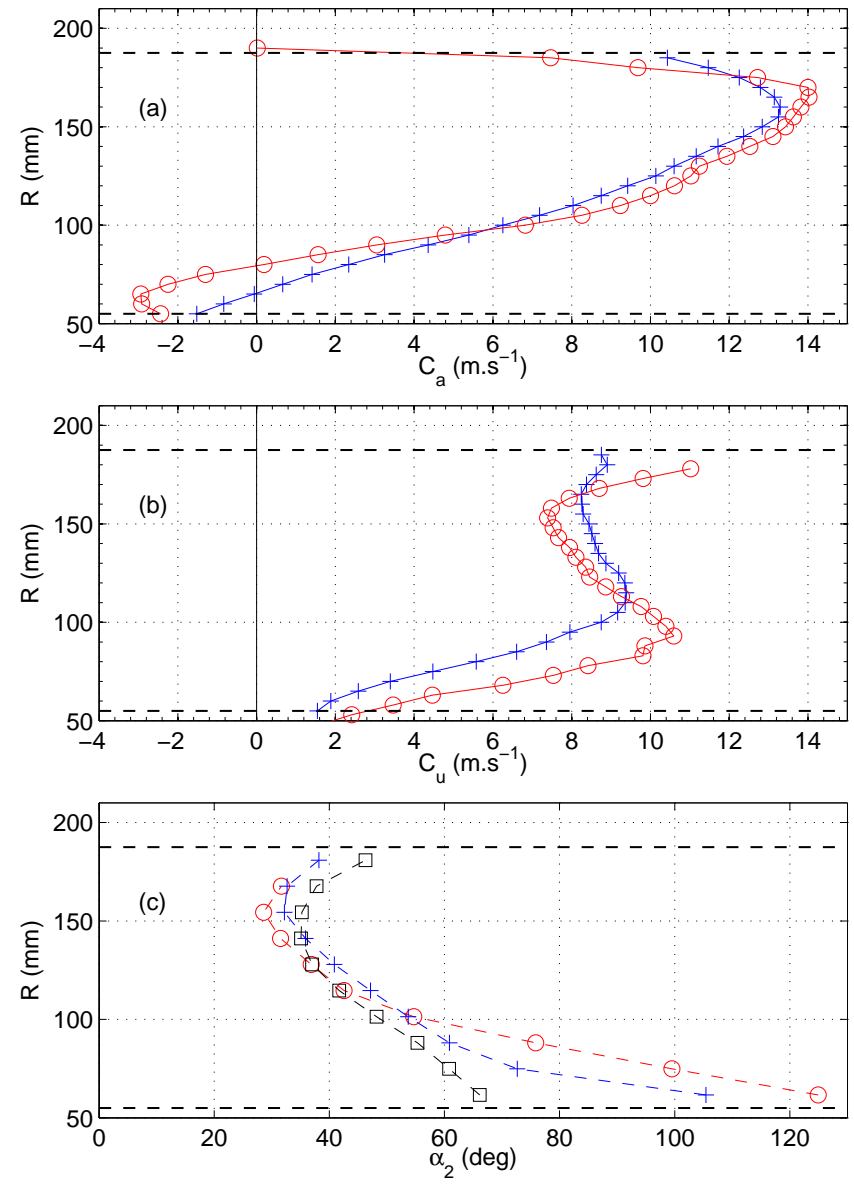

FIG. 6. Comparison of the radial profiles of the axial and tangential components, $C_{a}$ (a) and $C_{u}$ (b) and of the absolute flow angle $\alpha$ (c) respectively, $5 \mathrm{~mm}$ downstream of $\mathrm{FR}$ (red ○) and $175 \mathrm{~mm}$ downstream of FR (blue + ). The dashed lines represent the hub and the blade tip. $S=180 \mathrm{~mm}$, $N_{F R}=2000 \mathrm{rpm}$ and $\theta=0.9$. The black $\square$ in (c) stand for the predicted angles

tor but globally, the variation of the axial spacing does not affect drastically the mean velocity field close to FR. Let us examine the velocity evolution along the axial direction for a fixed spacing between the two rotors $S=180 \mathrm{~mm}$. The profiles of mean velocity at a distance $d=5 \mathrm{~mm}$ downstream of the front rotor and at a distance $d=5 \mathrm{~mm}$ upstream of the rear rotor are compared in Fig. 6. According to the axial components, the recirculating region is smaller near the rear rotor. Moreover, while traveling from the FR to $\mathrm{RR}$, the tangential component become more homogenized in the upper region. Again globally the velocity is not affected significantly which explain why the global performances do not drastically change when $S$ is increased to the maximum value that was explored in the present study. Finally, the profiles of the flow angle in the absolute reference frame are plotted in Fig. 6(c). The agreement between the predicted value on which the design of the rear rotor is based (black $\square$ ) and the angles just downstream of FR (red o) and just upstream of RR (blue + ) is at first sight very good. The angle is however slightly under-estimated close to the blade tip, and over-estimated close to the hub, in agreement with the discussion on the actual axial velocity profile.

In other studies ${ }^{3,4}$ it was reported that the axial spacing had a more significant influence on the overall performances. This was noticed as well in this study. In the present study, the global performance when $S=180 \mathrm{~mm}$ $(A=3.10)$ is still excellent (see Fig. 4). In the following paragraph, measurements of the wall pressure fluctuations and analysis of the velocity fluctuations are performed to check whether the axial spacing has an influence on more local quantities.

i. Wall pressure and velocity fluctuations The wall pressure fluctuations have been recorded for two axial spacings: $S=10$ and $S=150 \mathrm{~mm}$. For both configurations, four microphones were regularly spaced around the duct circumference and $5 \mathrm{~mm}$ downstream of the front rotor. Figure 7 shows the power spectral density for $S=10 \mathrm{~mm}$ (blue curve) and $S=150 \mathrm{~mm}$ (red curve).

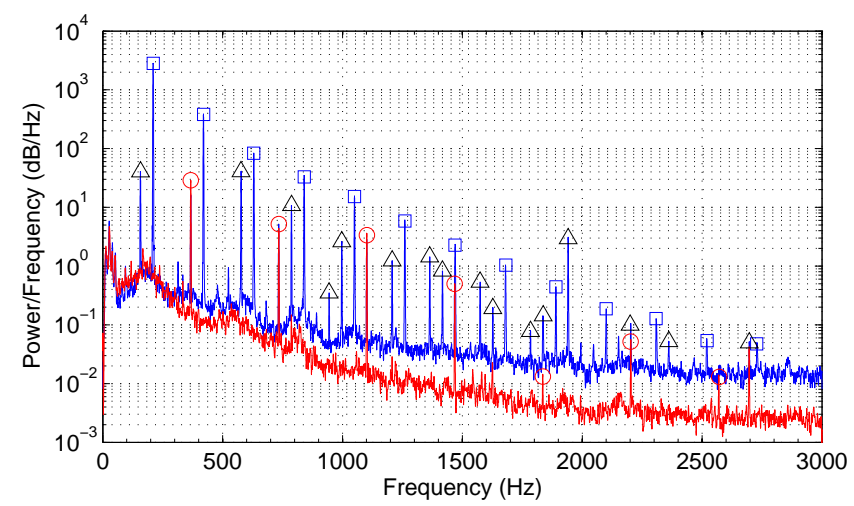

FIG. 7. Power spectral density of the wall pressure fluctuations $5 \mathrm{~mm}$ downstream the front rotor. The blue curve stands for the axial spacing $S=10 \mathrm{~mm}$ and the red curve for $S=150 \mathrm{~mm}$. The red $\circ$ stand for the blade passing frequency and the harmonics of the front rotor and and the blue $\square$ stand for that of the rear rotor. The black $\triangle$ stand for the various interactions of these frequencies

One can see that the blue curve has much more frequency components, higher peaks and higher signal-tonoise ratio than the red curve. Among those frequency peaks, there are the blade passing frequency (and its harmonics) of the front rotor: $\mathrm{f}_{b p F R}=11 \times 2000 / 60=$ $366.7 \mathrm{~Hz}$ and the the blade passing frequency (and its harmonics) of the rear rotor: $\mathrm{f}_{b p R R}=7 \times 1800 / 60=$ $210 \mathrm{~Hz}$. Please notice that $\mathrm{f}_{b p F R}$ peaks of the blue curve are hidden by those of the red curve. The peaks of the rear rotor blade passing frequencies are much higher than those of the front rotor despite the fact that the rear rotor rotation rate is lower than the front rotor rotation rate. This is consistent with the fact that the $R R$ has less blades than the FR and performs more static pressure rise than the $\mathrm{FR}$ alone (assuming that the FR does 
the same pressure rise with and without the RR). The RR's blades are therefore more loaded which results in higher peak levels as can be observed in Fig 7. Moreover, along the blade passing frequencies other peaks are visible for the shortest axial spacing (blue curve in Fig. 7). The corresponding frequencies are the interactions of the two rotors blade passing frequencies that are equal to:

$$
f=m \times f_{b p F R}+n \times f_{b p R R}
$$

where $m$ and $n$ are two integers. The same spectral analysis was carried out on signals from LDA measurements at two radii away from the wall duct $-R=120 \mathrm{~mm}$ and $R=170 \mathrm{~mm}-$ for $S=10 \mathrm{~mm}$. The results are plotted in Fig. 8. Again the blade passing frequencies of the front and rear rotors are well detected as well as some interaction frequencies. The strong interaction between the rotors is not only located near the wall but is also present along the blade height.

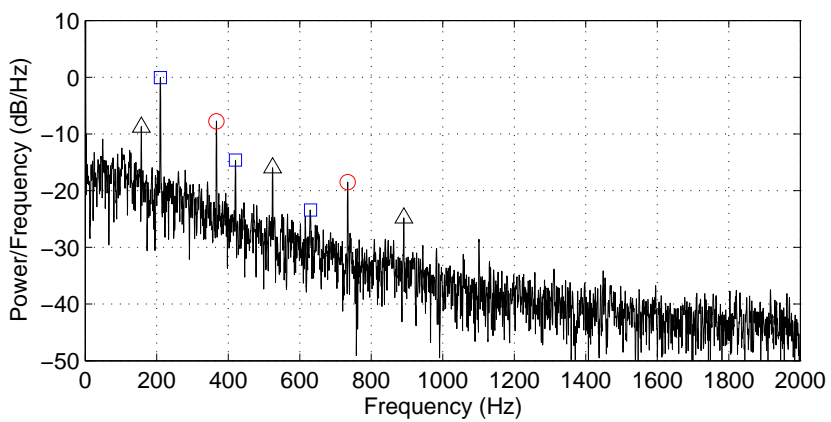

FIG. 8. Power spectral density of the LDA signals for $S=$ $10 \mathrm{~mm}, 5 \mathrm{~mm}$ downstream the front rotor at $R=120 \mathrm{~mm}$. The LDA signal is resampled before computing the PSD. The red $\circ$ and blue $\square$ stand for the blade passing frequencies and their harmonics of the front rotor and the rear rotor, respectively. The black $\triangle$ are the rotors interaction peaks

Figure 9 graphs the autocorrelation coefficients of the microphone number 2 (blue curve) and the crosscorrelation between microphone number 1 and 2 (green curve) for $\mathrm{S}=10 \mathrm{~mm}$. The rear rotor rotation direction is from microphone 1 to microphone 2. The abscissa axis represents the front rotor rotation (dimless): 1 corresponds to one revolution of the front rotor.

In the case of $S=10 \mathrm{~mm}$, both curves (blue and green) are periodic and highly correlated. The main period $t_{1}=$ $4.833 \mathrm{~ms}$ corresponds to $\mathrm{f}_{1}=210 \mathrm{~Hz}$. This is the blade passing frequency of the rear rotor, $\mathrm{f}_{b p R R}$. According to the cross-correlation curve, the flow structure near by the microphone number 1 is very similar to that of the microphone number 2 . The green curve is shifted by $t_{2}=t_{1} / 4$ and that is the time to go from microphone one to microphone two. This observation could mean that there is a strongly coherent structure (located at least in the tip region), travelling at the same rotation rate as the rear rotor and in the same direction. All these remarks

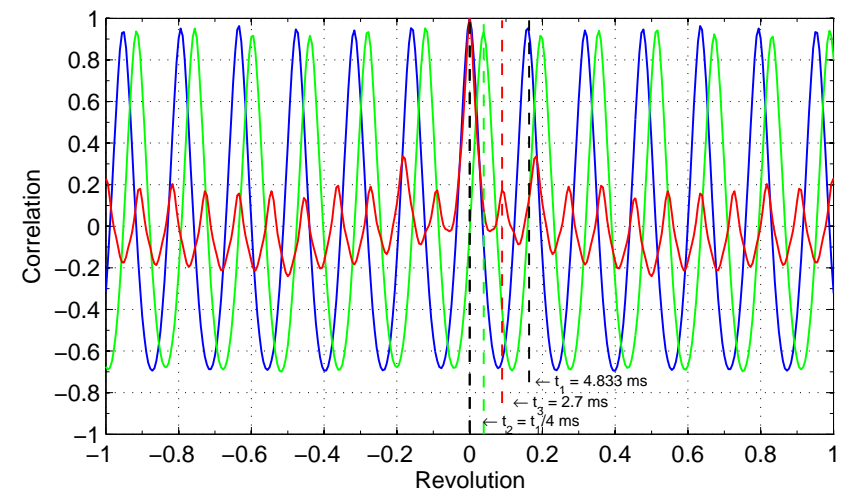

FIG. 9. Auto- and Cross-Correlation functions of the wall pressure fluctuations. The time on the abscissa axis is made dimensionless, i.e. $t^{\prime}=t * f_{F R}$ and represents two revolutions of the front rotor. The blue curve stands for the autocorrelation coefficients of the microphone 2 at $S=10 \mathrm{~mm}, \mathrm{t}_{1}$ being its main period. The green curve stands for the crosscorrelation of the microphones 1 and 2 at $S=10 \mathrm{~mm}, \mathrm{t}_{2}$ being the time lag of the first maximum of the green curve. The red curve stands for autocorrelation of the microphone 2 at $S=150 \mathrm{~mm}, \mathrm{t}_{3}$ being its period.

lead to think that the rear rotor generates and imposes its frequency to the flow structure in the inter-rotors region.

Let us now consider the case where $S=150 \mathrm{~mm}$. Recall that the microphones are still $5 \mathrm{~mm}$ downstream of the front rotor and thus $145 \mathrm{~mm}$ upstream of the rear rotor. The power spectral density in Fig 7 (red curve) shows only the blade passing frequencies of the front rotor. The blade passing frequencies of the rear rotor do not appear any more. The peaks level are noticeably the same. In the same way, the autocorrelation coefficients of the microphone number 2, red curve in Fig. 9, are very low for $S=150 \mathrm{~mm}$. One can count eleven periods on the red curve, and that is the number of blade of the front rotor and the period $t_{3}=2.7 \mathrm{~ms}$ corresponds to $\mathrm{f}_{3}=370.4 \mathrm{~Hz}$ which is very near to the front rotor blade passing frequency. It is clear from above that the interaction between rotors tends to decrease when increasing the axial spacing, at least, the FR does not see the influence of the RR. On the other hand, it does not mean that the $\mathrm{RR}$ does not contribute to the whole noise emission or that the rotors interaction does not exist anymore when the axial spacing is increased.

In the present study, the axial distance has thus much more important effects on local and fluctuating charcteristics of the system than on the global performances. This is very interesting for instance for an acoustic optimization.

\section{Influence of the rotation ratio $\theta$}

The overall performances of the CRS for various $\theta$ at a constant axial spacing $S=10 \mathrm{~mm}$ and at a constant 

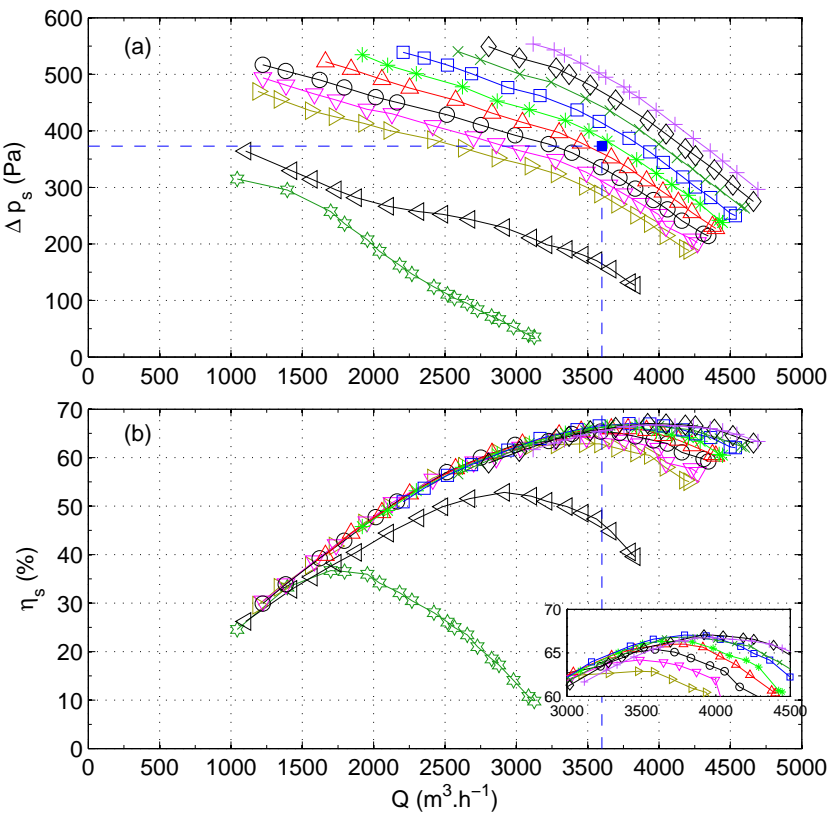

FIG. 10. CRS characteristics at $N_{F R}=2000 \mathrm{rpm}, S=10 \mathrm{~mm}$ and $\theta \in[0 ; 1.2]$ : (a) static pressure rise $\Delta p_{s}$ vs flow rate $Q$; (b) static efficiency $\eta_{s}$ vs flow rate $Q$. Dark green $\nLeftarrow$ : $\theta=0$, black $\triangleleft: \theta=0.5$, mustard yellow $\triangleright: \theta=0.8$, magenta $\nabla$ : $\theta=0.85$, black $\circ: \theta=0.9$, red $\triangle: \theta=0.95$, green $*: \theta=1$, blue $\square: \theta=1.05$, dark green $\times: \theta=1.1$, black $\diamond: \theta=1.15$ and purple $+: \theta=1.2$. The blue $\boldsymbol{\square}$ and the dashed lines stand for the design point of the CRS

$N_{F R}=2000 \mathrm{rpm}$ are plotted in Fig. 10. As expected, the more the rotation rate of $\mathrm{RR}$ increases, the more the static pressure rise of the CRS increases and the nominal flow-rate of the CRS increases. The maximal static efficiency and the corresponding nominal flow-rate as a function of $\theta$ are moreover plotted in Fig. 11 (black o: $N_{F R}=2000 \mathrm{rpm}$ ).

For very low rotation rates of RR, i.e. for $\theta=0$ (Dark green $\diamond$ in Fig. 10) and $\theta=0.5$ (black $\triangleleft$ in Fig. 10), the system is very unefficient: in the first case when the $\mathrm{RR}$ is at rest the maximum efficiency hardly reaches $35 \%$ which is below the maximal efficiencies of both FR and $\mathrm{RR}$ alone. The maximum flow-rate that can be reached is moreover very low in both cases compared to the discharge goal of $3600 \mathrm{~m}^{3} \cdot \mathrm{h}^{-1}$.

In the range $\theta \in[0.8 ; 1.2]$, i.e. $N_{R R} \in$ $[1600 ; 2400] \mathrm{rpm}$ for $N_{F R}=2000 \mathrm{rpm}$, the system is highly efficient. The maximum efficiency slightly increases with $\theta$ to reach a maximum value of $67 \pm 1 \%$ for $\theta \in[1.05 ; 1.15]$ and then seems to decrease slightly $\left(\eta_{s}=66 \pm 1 \%\right.$ for $\left.\theta=1.20\right)$.

On the one hand, this is a very interesting feature of the counter-rotating system. One could imagine, simply by varying the rear rotor rotation rate, to work at a constant pressure rise with an efficiency greater than $60 \%$ for a large flow-rate range. For instance in the present
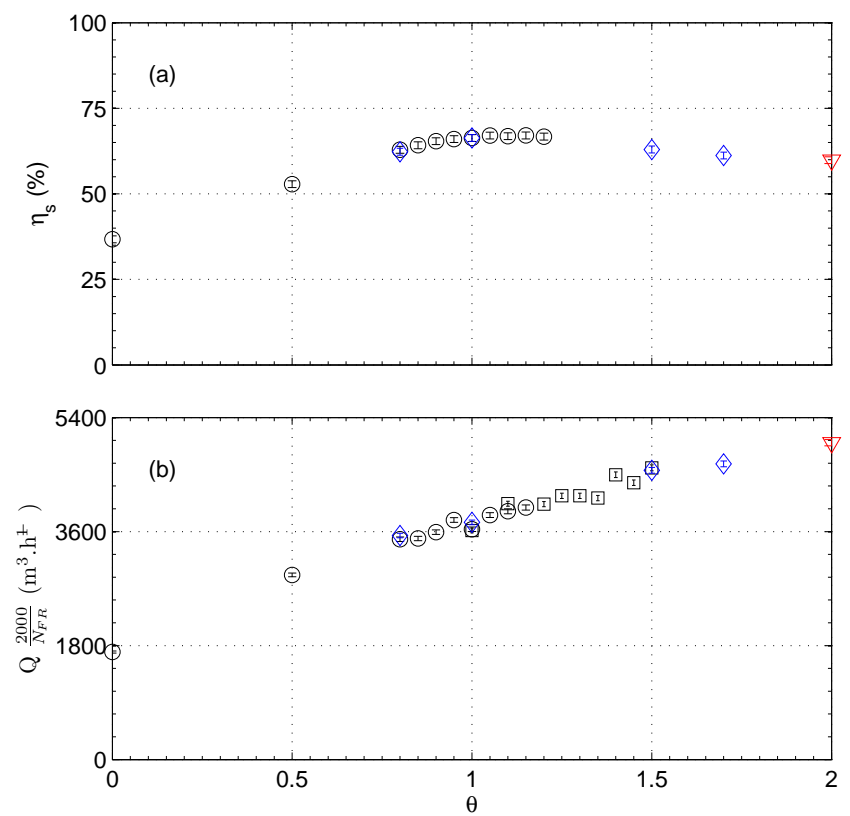

FIG. 11. Maximal static efficiency $\eta_{s}$ (a) and corresponding nominal flow-rate $Q$ (b) vs $\theta$ for the CRS with $S=10 \mathrm{~mm}$. Black o: $N_{F R}=2000 \mathrm{rpm}$, blue $\diamond: N_{F R}=1600 \mathrm{rpm}$ and red $\nabla: N_{F R}=1300 \mathrm{rpm}$. Please note that the presented nominal flow-rate has been scaled by $2000 / N_{F R}$

case, the system could give a constant static pressure rise of $375 \mathrm{~Pa}$ with $\eta_{s} \geq 60 \%$ for $3000 \leq Q \leq 4250 \mathrm{~m}^{3} \cdot \mathrm{h}^{-1}$ with $N_{F R}=2000 \mathrm{rpm}, S=10 \mathrm{~mm}$ and $\theta \in[0.85 ; 1.2]$. One could also imagine to work at a constant flowrate with high static efficiency. For instance in the present case, the system could give a constant flow-rate of $3600 \mathrm{~m}^{3} \cdot \mathrm{h}^{-1}$ with $\eta_{s} \geq 60 \%$ for $290 \leq \Delta p_{s} \leq 490 \mathrm{~Pa}$ with $N_{F R}=2000 \mathrm{rpm}, \bar{S}=10 \mathrm{~mm}$ and $\theta \in[0.8 ; 1.2]$.

On the other hand, the maximum of the best efficiencies as a function of $\theta$ is not reached at the design point $(\theta=0.9)$, but for a slightly greater ratio of the rotation rates. This point requires further studies and the first question that is adressed is until which value the rear rotor can be accelerated keeping a great efficiency of the system. In order to extend the range of explored $\theta$ to $\theta>1.2$, it is necessary to reduce the rotation rate of the front rotor, because of the maximal power that the motors can deliver. The maximum efficiency for four values of $\theta$ at $N_{F R}=1600 \mathrm{rpm}$ (blue $\times$ ) and for $\theta=2$ at $N_{F R}=1300 \mathrm{rpm}(\mathrm{red}+)$ are plotted in Fig. 11(a) together with the values previously discussed and that were obtained at $N_{F R}=2000 \mathrm{rpm}$ (black o). For $\theta=0.8$ and $\theta=1$, the two values are equal to those that were measured with $N_{F R}=2000 \mathrm{rpm}$. The ratio $Q / N_{F R}$ is moreover the same for those two points as can be seen in Fig. 11(b): the efficiency thus does not depend on the Reynolds number in the explored range (at mid-span, the Reynolds number is $R e=3 \times 10^{5}$ at $N_{F R}=2000 \mathrm{rpm}$ and $R e=2.4 \times 10^{5}$ at $N_{F R}=1600 \mathrm{rpm}$ ). This may be 
the same for $N_{F R}=1300 \mathrm{rpm}$ with $R e=2 \times 10^{5}$.

The maximal efficiency for $\theta>1.2$ decreases (see Fig. 11) as could be expected but surprisingly, the maximal efficiency at $\theta=2$ is still quite high: $\eta_{s}(\theta=2)=$ $60 \pm 1 \%$.

The measurement of the velocity field between the two rotors that have been presented in $\S$ IV B may help to understand these features. At $\theta=0.9$ and $Q=1 \mathrm{~m}^{3} \cdot \mathrm{s}^{-1}$, the measured angles on the upper part of the blades are indeed smaller than the prediction on which the design of $\mathrm{RR}$ is based. In order to match the design, the RR requires more tangential velocity (see the velocity triangles in Fig. 1). This may explain why the maximal efficiency first increases when $\theta>0.9$. On the other hand, the faster RR rotates, the higher the discharge flow should be to match the velocity triangle. The flow-rate at which the system is the most efficient indeed quasi linearly increases with $\theta$ (see Fig. 11(b)). However in this case the front rotor is in an overflow regime. This rotor then gives reduced pressure rise and lower tangential component in the exit flow. This is consistent with the decrease of the maximal efficiency for greater $\theta$. The charcteristic curve of FR (see red $\square$ in Fig. 3) being very flat, this could also explain why the system is still so efficient for relatively large values of $\theta$.

The last question that is dicussed is whether the flow at the exit of the CRS is solely axial at the design point or not, and to what extent the exit absolute flow angles are correlated to the behaviour of the system at the nominal points when varying $\theta$.

The flow angle downstream of the CRS has been measured by image processing. A wind vane of length $100 \mathrm{~mm}$, of thickness $1.5 \mathrm{~mm}$ and of width $10 \mathrm{~mm}$ has been placed between the CRS and the anti-gyration device, at a radius $160 \mathrm{~mm}$. It is illuminated from beneath with a LED plate and imaged from above with a high-speed video camera (Optronis CamRecord 600) at $250 \mathrm{~Hz}$. The images are then treated with algorithm described in Ref. ${ }^{14}$ after normalization with a background image. An equivalent ellipsoid is fitted, the orientation of which is computed. The measured angle is stable within \pm 1 degree. The results are plotted in Fig. 12. The negative orientation corresponds to the direction of rotation of $\mathrm{FR}$, and the positive orientation to the direction of rotation of RR. At the design point $\theta=0.9$, the exit-flow still has a non negligible rotating component $\left(\alpha \simeq-15^{\circ}\right)$, indicating that the RR does not completely straighten the flow. The angle is reduced when increasing $\theta$ and $\alpha=0^{\circ}$ is obtained for $\theta \simeq 1.2$. The swirl is then reversed in the direction given by $\mathrm{RR}$ for $\theta>1.2$. One can furthermore notice that the angle varies linearly with $\theta$ and that $\alpha$ and $\eta_{s}$ are highly correlated (see inset in Fig. 12). Efficiencies greater than $62 \%$ are obtained for $\theta \in[0.8 ; 1.7]$ corresponding to $\alpha \in\left[-22^{\circ} ; 22^{\circ}\right]$. The range of flowrates that could be riched with a very high efficiency is thus extremely high.
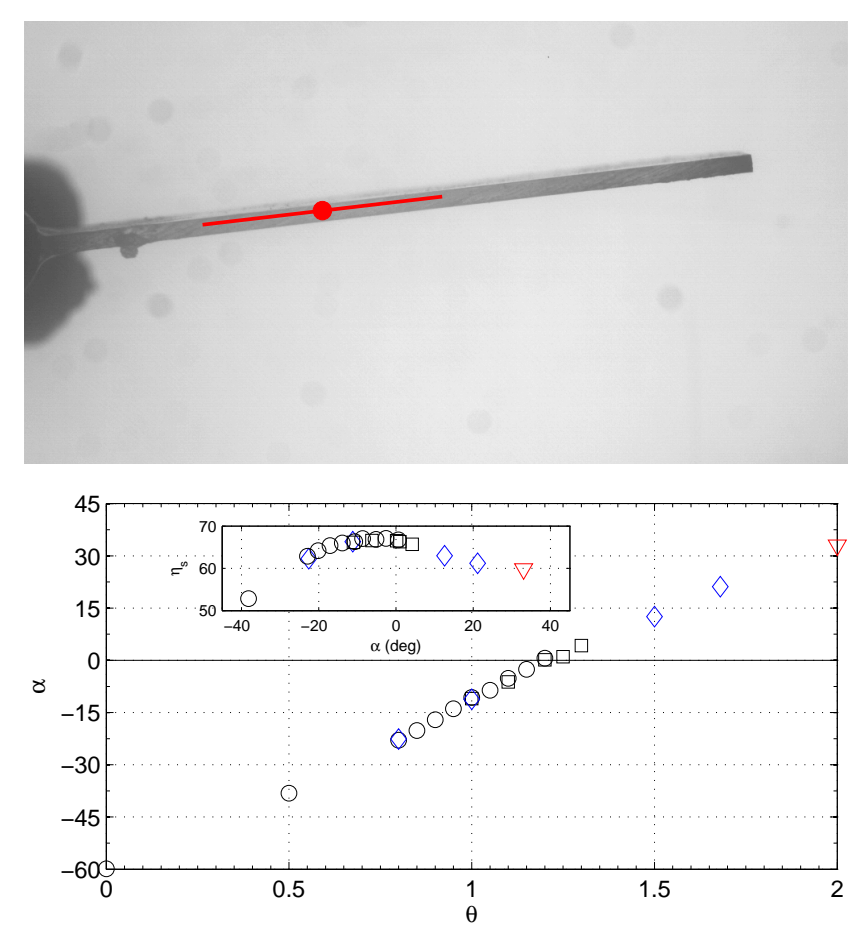

FIG. 12. Measurement of the absolute flow angle $\alpha_{2 C R S}$ with image processing. Example of the processing with the detected centroid (red o) and the equivalent ellipsoid great axis (straight red line). Absolute flow angle $\alpha$ at the nominal flowrate vs $\theta$. Inset: static efficiency at the nominal flow rate $\eta_{s}$ vs $\alpha$ for the same data set. Black o: $N_{F R}=2000 \mathrm{rpm}$, black $\square: N_{F R}=1800 \mathrm{rpm}$, blue $\diamond: N_{F R}=1600 \mathrm{rpm}$ and red $\nabla:$ $N_{F R}=1300 \mathrm{rpm}$

\section{CONCLUSION}

A counter-rotating axial-flow fan has been designed according to an iterative method that is relatively fast. It is based on semi-empirical modelization that partly takes into account the losses, boundary layers at hub and casing, and the effects of "low" Reynolds numbers (below $\left.2 \times 10^{5}\right)$.

The overall performances at the nominal design point are slightly lower than predicted, with a static pressure rise $10.2 \%$ lower. The static efficiency is however remarkably high $\left(\eta_{s} \simeq 65 \%\right)$ and corresponds to a 20 points gain in efficiency with respect to the front rotor maximal efficiency and to a 10 points gain with respect to the rear rotor.

The overall measurements give first clues that allow to validate the design method. Local measurements of the velocity field and flow visualization show that the simplified radial equilibrium hypothesis used in the design method is responsible for the slight under-prediction. However, the variation of axial distances from a relative to the chord $A \in[0.17 ; 3.10]$ quite surprinsingly does not affect the overall performances so much. The best efficient configuration is moreover obtained for a small 
increase of the rear rotor rotation rate, which is consistent with the velocity field measurements and with the visualizations.

The counter-rotating system has furthermore a very flexible use that allows to work at constant flow-rate on a wide range of static pressure rises or to work at constant pressure rise on a wide range of flow-rates, with static efficiency bigger than $60 \%$, simply by varying the rear rotor rotation rate. One could thus imagine an efficient closed-loop-controlled axial-flow fan. Besides, this feature may not be general but related to the flat characteristic of the front rotor in the present system. Other studies with a different design of the front rotor (other load distribution, thickening of the blades ${ }^{13}$ ) may give answers to this point.

Finally, the wall pressure fluctuations investigation, which is representative of the very near-field noise emission, shows a strong influence of the rear rotor over the flow structure between rotors when they are close to each other. The spectral composition of the fluctuating pressure is very sensitive to the axial spacing. An increase of $A$ leads to a suppression of the rotors interaction peaks close to the FR without decreasing a lot the overall performances. This parameter can thus be of great interest with respect to an acoustic optimization problem. These results are encouraging to study deeper the effect of the axial spacing on the far-field noise emission.

\section{ACKNOWLEDGMENT}

The authors finally wish to thank Robert Rey for very fruitful discussions.

\section{NOMENCLATURE}

Flow angle in the absolute reference frame.

Flow angle in the relative reference frame.

$\mathcal{D} \quad$ Lieblein's diffusion factor.

$\Delta p \quad$ Pressure rise.

$\eta \quad$ Efficiency.

$\Omega \quad$ Specific speed.

$\omega \quad$ Angular velocity.

$\rho \quad$ Density.

$\sigma \quad$ Blade solidity.

$\theta \quad$ Rotation ratio $\frac{N_{R R}}{N_{F R}}$.

1 Fan inlet

$2 \quad$ Fan outlet

A Relative axial spacing, $S / c$.
Axial coordinate

atm

C Flow velocity in the absolute reference frame.

c Chord length.

$\mathrm{C}_{z \infty 0}$ Camber coefficient.

CRS Counter-rotating system.

D Ducting pipe diameter.

est Estimate

FR Front rotor.

m Mean

$\mathrm{N} \quad$ Rotation rate in $\mathrm{rpm}$.

Q Flow rate.

$\mathrm{R} \quad$ Blade radius.

r Radial coordinate

RR Rear rotor.

S Axial spacing.

s $\quad$ Static pressure

$\mathrm{T} \quad$ Torque supplied by the shaft.

$\mathrm{t}$ Total pressure

$\mathrm{U} \quad$ Velocity of the moving reference frame.

u Tangential coordinate

W Flow velocity in the relative reference frame.

Z Number of blades.

${ }^{1}$ Lesley, E., 1933. Experiments with a counter-propeller. Tech. Rep. 453, National Advisory Committee for Aeronautics.

${ }^{2}$ Lesley, E., 1939. Tandem air propellers. Tech. Rep. 689, National Advisory Committee for Aeronautics.

${ }^{3}$ Sharma, P., Jain, Y., and Pundhir, D., 1988. "A study of some factors affecting the performance of a contra-rotating axial compressor stage". Proceedings of the Institution of Mechanical Engineers. Part A. Power and process engineering, 202, pp. 15-21. ${ }^{4}$ Sharma, P., Pundhir, D., and Chaudhry, K., 1991. "A study of aeroacoustic performance of a contra-rotating axial flow compressor stage". Def Sci J, 41, pp. 165-180.

${ }^{5}$ Min, K.-S., Chang, B.-J., and Seo, H.-W., 2009. "Study on the contra-rotating propeller system design and full-scale performance prediction method". International Journal of Naval Architecture and Ocean Engineering, 1, pp. 29-38.

${ }^{6}$ Shigemitsu, T., Furukawa, A., Watanabe, S., Okuma, K., and Fukutomi, J., 2009. "Internal flow measurement with ldv at design point of contra-rotating axial flow pump". Journal of Fluid Science and Technology, 4, pp. 723-734.

${ }^{7}$ Shigemitsu, T., Fukutomi, J., and Okabe, Y., 2010. "Performance and flow condition of small-sized axial fan and adoption of contra-rotating rotors". Journal of Thermal Science, 19, pp. $1-6$. 
${ }^{8}$ Shigemitsu, A., Watanabe, T., and Furukawa, S., 2007. "Performance test and flow measurement of contra-rotating axial flow pump". Journal of Thermal Science, 16(1), pp. 7-13.

${ }^{9}$ Pin, L., Yingzi, J., and Yanping, W., 2011. "Effects of rotors structure on performance of small size axial flow fans". Journal of Thermal Science, 20, pp. 205-210.

${ }^{10}$ Nouri, H., Ravelet, F., Bakir, F., and Sarraf, C., 2011. "Experimental investigation on ducted counter-rotating axial flow fans". ASME Conference Proceedings, 2011, pp. 783-791 doi:10.1115/AJK2011-22061.

${ }^{11}$ Noguera, R., Rey, R., Massouh, F., Bakir, F., and Kouidri, S., 1993. "Design and analysis of axial pumps". In ASME Fluids Engineering, Second Pumping Machinery Symposium, Washington, USA., pp. 95-111.

${ }^{12}$ ISO, 2007. ISO 5801 - Industrial fans Performance testing using standardized airways. International Standards for Business,
Government and Society.

${ }^{13}$ Sarraf, C., Nouri, H., Ravelet, F., and Bakir, F., 2011. "Experimental study of blade thickness effects on the global and local performances of a controlled vortex designed axial-flow fan". Experimental Thermal and Fluid Science, 35, p. 684.

${ }^{14}$ Ravelet, F., Colin, C., and Risso, F., 2011. "On the dynamics and breakup of a bubble rising in a turbulent flow". Physics of Fluids, 23, p. 103301.

${ }^{15}$ Moreau, S., and Bakir, F., 2002. "Efficient stator designed for automotive engine cooling fan systems". In ASME 2002 Fluids Engineering Division Summer Meeting, pp. FEDSM02-31318.

${ }^{16}$ Bakir, F., and Moreau, S., 2003. "Detailed study of an efficient small diameter automotive engine cooling fan system". In ASME 2003 Fluids Engineering Division Summer Meeting, pp. FEDSM2003-45117. 